\title{
CARACTERÍSTICAS MORFOLÓGICAS E VARIABILIDADE GENÉTICA DE ARATICUM UTILIZANDO MARCADORES RAPD E MICROSSATÉLITES ${ }^{1}$
}

\author{
MARCELA VERSIANI VENÂNCIO PIRES ${ }^{2}$, FÁBIO GELAPE FALEIRO ${ }^{3}$, \\ JOSÉ CARLOS SOUSA SILVA ${ }^{3}$, JOSÉ TEODORO DE MELO ${ }^{3}$, JOSÉ RICARDO PEIXOTO ${ }^{4}$
}

RESUMO - Neste trabalho, objetivou-se avaliar a variabilidade genética da coleção de trabalho de acessos de araticum da Embrapa Cerrados e outros materiais próximos ao Distrito Federal, utilizando marcadores moleculares RAPD, microssatélites e análise de características morfológicas. Folhas de 18 acessos de araticum foram coletadas e utilizadas para a extração das amostras de DNA genômico, as quais foram amplificadas para obtenção de marcadores moleculares RAPD e microssatélites. Na análise morfológica, foram avaliadas 23 características dos acessos de araticum. As dissimilaridades genéticas entre os 18 genótipos de araticum evidenciaram a variabilidade genética dos acessos e as análises de agrupamento levaram à formação de três grupos de similaridade. Verificaram-se coeficientes de dissimilaridades genéticas baixos entre os materiais oriundos da Embrapa Cerrados e altos entre os outros materiais. Esses acessos são importantes fontes de variabilidade para o enriquecimento da atual coleção de trabalho da Embrapa Cerrados e para futuros estudos de caracterização morfológica e agronômica.

Termos para indexação: marcadores moleculares, SSR, caracterização, recursos genéticos.

\section{MORPHOLOGICAL CHARACTERISTICS AND GENETIC VARIABILITY OF ARATICUM USING RAPD AND MICROSATELLITES MARKERS}

\begin{abstract}
This study aimed to evaluate the genetic variability of the araticum collections from Embrapa Cerrados and others regions near to the Federal District, using RAPD and microsatellites markers as well as morphological analysis. Young leaves of 18 araticum accessions were collected and used for genomic DNA extraction. Genomic DNA samples from each accession were amplified for obtaining RAPD and microsatellites markers. Morphological analysis were performed using 23 characteristics of each araticum accession. Genetic dissimilarities among the 18 araticum accessions showed high genetic variability among them and cluster analysis led to the formation of three similarity groups. It was observed low genetic dissimilarities among accessions from Embrapa Cerrados and high genetic dissimilarities among accessions from others regions. These accessions are important as genetic variability sources to enlarge the current Embrapa Cerrados collection and for future studies of morphological and agronomic germplasm characterization.
\end{abstract}

Index terms: molecular markers, SSR, characterization, genetic resources.

\footnotetext{
1(Trabalho 075-14). Recebido em: 28-02-2014. Aceito para publicação em:. 16-10-2014.

${ }^{2}$ Eng. Agr. Mestre em Agronomia/Universidade de Brasília, Brasília-DF. Apoio financeiro: CAPES e Embrapa Cerrados. E-mail: maversiani@yahoo.com.br.

${ }_{3}^{3}$ Pesquisador da Embrapa Cerrados, BR 020, Km 18, C. P. 08223, 73010-970, Planaltina-DF. E-mail: fabio.faleiro@embrapa.br; jose. sousa-silva@embrapa.br; teodoro.melo@embrapa.br.

${ }^{4}$ Professor Professor da Faculdade de Agronomia e Medicina Veterinária da Universidade de Brasília, C. P. 04508, 70910-970, BrasíliaDF. E-mail: peixoto@unb.br
} 


\section{INTRODUÇÃO}

$\mathrm{O}$ araticum (Annona crassiflora Mart.) é uma espécie frutífera da família Annonaceae, nativa da região do Cerrado, estudada atualmente em diversas áreas, desde a culinária, como fonte nutricional, até a medicinal, pelo grande potencial antioxidante, além da obtenção de extratos com diferentes finalidades (ALMEIDA et al., 1998; ROESLER et al., 2007; INOUE et. al., 2010).

No Bioma Cerrado, o araticum ocorre em maior densidade na fitofisionomia chamada de Cerrado Típico, localizado nos Latossolos, tendendo a ocupar áreas mais altas dos Chapadões. Em quatorze áreas amostradas no Estado de Goiás, Mesquista et al. (2007) verificaram a ocorrência média de 63,14 plantas de araticum por hectare, sendo que a maioria das áreas estava localizada em altitudes acima de 800 $\mathrm{m}$, apresentando solos classificados como de nível baixo a muito baixo para os principais nutrientes ( $\mathrm{P}, \mathrm{Ca}, \mathrm{Mg}, \mathrm{K}$ e $\mathrm{Zn}$ ) e de nível médio a alto de $\mathrm{Al}$. Trata-se, portanto, de uma planta rústica, embora sua área basal total seja influenciada positivamente pelos níveis de $\mathrm{Ca}, \mathrm{Mg}$ e $\mathrm{K}$ no solo (MESQUITA et al., 2007). Para a conservação, caracterização e uso de plantas nativas do Cerrado como o araticum, o estabelecimento de bancos de germoplasma, ajustes no processo de domesticação e estabelecimento de plantios comerciais são de grande importância como alternativas também para o extrativismo predatório (JUNQUEIRA et al., 2008; FALEIRO et al., 2011). Para a produção de mudas de araticum, Oliveira et al. (2010) recomendam que as sementes sejam imersas em solução com ácido giberélico a $0,1 \%$, por 24 horas, para iniciarem a germinação com 25 a 50 dias, atingindo uma taxa 30 a $40 \%$. As sementes de araticum apresentam germinação lenta e desuniforme, o que afeta negativamente sua propagação (BERNADES et al., 2007; BLANCO et al., 2007). Além da produção de mudas, outros ajustes devem ser feitos no sistema de produção visando à domesticação da espécie (JUNQUEIRA et al., 2008).

$\mathrm{O}$ araticum é uma planta diploide $(2 \mathrm{n}=14)$ (RIBEIRO, 2012), preferencialmente alógama, com plantas funcionais reprodutivas masculinas, femininas e hermafroditas (CAVALCANTE et al., 2009), podendo apresentar certo grau de autofecundação, variando de 5 a 50\% (PEREIRA et al., 2008), ou seja, a fecundação é preferencialmente realizada por meio da polinização cruzada, não havendo a formação de frutos por apomixia (CAVALCANTI et al., 2009).

Estudos sobre a variabilidade genética de diferentes acessos da espécie geram importantes informações para subsidiar diferentes práticas de manejo, estabelecimento e manejo de bancos de germoplasma e também etapas iniciais de seleção e melhoramento genético (FALEIRO, 2007). Características morfológicas, agronômicas e moleculares são normalmente utilizadas nos estudos de variabilidade genética. Pereira et al. (2008) constataram elevado nível de variabilidade genética em populações naturais de $A$. crassiflora no Estado de Goiás, com base na observação de grande número de alelos em locos de marcadores moleculares microssatélites ou SSR (Simple Sequence Repeats). Tal variabilidade genética molecular também foi verificada por Cota et al. (2011) que estudaram populações desta espécie na região norte do Estado de Minas Gerais, utilizando marcadores moleculares RAPD (Random Amplified Polymorphic DNA). No trabalho de Cota et al. (2011), verificou-se que a variabilidade genética dentro de populações foi maior que a variabilidade genética entre as populações avaliadas. Ferreira (2011) também observou alta taxa de divergência genética de populações de araticum no Estado de Minas Gerais, utilizando marcadores moleculares microssatélites, evidenciando a importância da conservação genética dessas populações.

Considerando as potencialidades da espécie e a importância dos estudos sobre a variabilidade genética, a Embrapa Cerrados tem trabalhado a caracterização morfológica e agronômica de coleções de trabalho de araticum. Para complementar tais estudos, neste trabalho, objetivou-se caracterizar e quantificar a variabilidade genética de coleções de trabalho de araticum utilizando características morfológicas categóricas, marcadores moleculares RAPD e microssatélites, analisando a importância da morfologia e dos marcadores moleculares na caracterização desses recursos genéticos.

\section{MATERIAL E MÉTODOS}

\section{Material genético}

Os materiais genéticos de araticum analisados foram 18 acessos, sendo 7 da coleção de trabalho da Embrapa Cerrados e outros de localidades próximas ao Distrito Federal. Dois acessos de Annona spp. foram utilizados como outgroup para análise geral da qualidade das informações geradas pelas características morfológicas e moleculares (Tabela 1).

Obtenção e análise de marcadores RAPD

Folhas de cada um dos 18 acessos foram coletadas e utilizadas no mesmo dia para extração de amostras de DNA genômico utilizando o método do 
CTAB, com modificações (FALEIRO et al., 2003). Amostras de DNA de cada material genético foram amplificadas via Reação em Cadeia da Polimerase para obtenção de marcadores moleculares RAPD. As reações de amplificação foram feitas em um volume total de $13 \mu \mathrm{L}$, contendo Tris-HCl $10 \mathrm{mM}$ (pH 8,3); $\mathrm{KCl} 50 \mathrm{mM}$; MgCl2 3 mM; $100 \mu \mathrm{M}$ de cada um dos desoxiribonucleotídios (dATP, dTTP, dGTP e dCTP), $0,4 \mu \mathrm{M}$ de um iniciador (Operon Technologies Inc., Alameda, CA, EUA); uma unidade da enzima Taq polimerase, e, aproximadamente, $15 \eta \mathrm{g}$ de DNA. Para a obtenção dos marcadores RAPD, foram utilizados 10 iniciadores decâmeros: OPD-05, OPD07, OPD-08, OPD-16, OPE-16, OPF-01, OPF-16, OPG-05, OPH-07 e OPH-08.

As amplificações foram efetuadas em termociclador programado para 40 ciclos, cada um constituído pela seguinte sequência: 15 segundos a 94 ${ }^{\circ} \mathrm{C} ; 30$ segundos a $35^{\circ} \mathrm{C}$, e 90 segundos a $72{ }^{\circ} \mathrm{C}$. Após os 40 ciclos, foi feita uma etapa de extensão final de seis minutos, a $72{ }^{\circ} \mathrm{C}$, e, finalmente, a temperatura foi reduzida para $4{ }^{\circ} \mathrm{C}$. Após a amplificação, foram adicionados, a cada amostra, $3 \mu \mathrm{l}$ de uma mistura de azul de bromofenol (0,25\%) e glicerol $(60 \%)$ em água. Essas amostras foram aplicadas em gel de agarose $(1,2 \%)$, corado com brometo de etídio, submerso em tampão TBE (Tris-Borato $90 \mathrm{mM}$, EDTA $1 \mathrm{mM}$ ). A separação eletroforética foi de, aproximadamente, quatro horas, a 90 volts. Ao término da corrida, os géis foram fotografados sob luz ultravioleta.

Os produtos das reações de amplificação (marcadores RAPD) foram codificados em presença (1) e ausência (0) de bandas e convertidos em uma matriz de dados binários, a partir da qual foram estimadas as dissimilaridades genéticas entre os diferentes acessos, com base no complemento do coeficiente de similaridade de Nei e Li, utilizando-se do Programa Genes (CRUZ, 2008).

\section{Obtenção e análise de marcadores microssatélites}

Na Tabela 2, são apresentados os iniciadores utilizados para a caracterização dos acessos de araticum, com suas respectivas sequências e temperaturas de anelamento, os quais foram desenvolvidos a partir de uma biblioteca genômica enriquecida, construída para A. crassiflora por Pereira et al. (2008).

A partir das amostras de DNA, as reações de amplificação foram feitas em um volume total de $13 \mu \mathrm{l}$, contendo Tris- $\mathrm{HCl} 10 \mathrm{mM}$ (pH 8,3); KCl $50 \mathrm{mM} ; \mathrm{MgCl}_{2} 2,4 \mathrm{mM} ; 150 \mu \mathrm{M}$ de cada um dos desoxinucleotídios (dATP, dTTP, dGTP e dCTP); 3 pM de cada um dos iniciadores; uma unidade da enzima Taq polimerase, e, aproximadamente, 30 $\eta \mathrm{g}$ de DNA. As amplificações foram efetuadas em termociclador, de acordo com o seguinte programa: $94{ }^{\circ} \mathrm{C}$ por 5 min para desnaturação; 30 ciclos de 1 $\min$ a $94^{\circ} \mathrm{C} ; 1 \mathrm{~min}$ a $55^{\circ} \mathrm{C}$, e $1 \min$ a $72^{\circ} \mathrm{C}$, e, ao final, uma etapa de extensão de 10 minutos a $72^{\circ} \mathrm{C}$. Ao final da amplificação, a temperatura das amostras foi reduzida a $4^{\circ} \mathrm{C}$.

Após o procedimento, foram adicionados, a cada amostra, $3 \mu \mathrm{l}$ de uma mistura de azul de bromofenol (0,25\%), glicerol (60\%) e água (39,75\%). Essas amostras foram aplicadas em gel de agarose a $3 \%$, corado com brometo de etídio $(0,2 \mu \mathrm{g} / \mathrm{mL})$, para separação dos fragmentos microssatélites. $\mathrm{O}$ gel foi submerso em tampão TBE (Tris-Borato 90 mM, EDTA $1 \mathrm{mM}$ ), e a separação eletroforética foi de, aproximadamente, quatro horas, a 100 volts. Ao término da corrida, os géis foram fotografados sob luz ultravioleta.

Os marcadores gerados foram convertidos em matrizes numéricas codificadas, a partir das quais foi possível calcular as dissimilaridades genéticas entre os materiais e realizar análises de agrupamento. A codificação foi realizada para cada loco, identificando os alelos presentes. Tal codificação é composta por dois números representando os alelos, sendo que dois números iguais significam que o loco está em homozigose (apresenta duas cópias do mesmo alelo) e dois números diferentes, que o loco está em heterozigose (apresenta dois alelos diferentes).

As dissimilaridades genéticas obtidas a partir dos marcadores microssatélites foram calculadas com auxílio do Programa Genes (CRUZ, 2008), baseandose na seguinte fórmula:

DGij = 1- (NLC/NTL) sendo:

DGij $=$ Dissimilaridade genética entre os acessos i e j;

NLC $=$ Número de Locos Coincidentes entre os acessos i e j;

NTL $=$ Número Total de Locos.

O NLC é o somatório das coincidências alélicas de cada loco analisado, sendo que cada coincidência pode assumir o valor 1 (dois alelos coincidentes); 0,5 (um alelo coincidente) e 0 (nenhum alelo coincidente).

\section{Obtenção e análise de características morfológicas categóricas}

Foram avaliadas 23 características das árvores de araticum, com relação ao fuste (crescimento, aspecto e cor); ritidoma (cor e tipo); copa (formato); folha (exsudação, disposição, filotaxia, forma, dimensão do pecíolo); lâmina foliar (margem, ápice, base, pilosidade, relação comprimento/largura, textura, estípula, coloração, 
nervação adaxial e abaxial e formato), e ramo (características). Os dados coletados de cada árvore foram categorizados em diferentes classes relacionadas na Tabela 3. Os valores das classes em cada característica de acessos individualizados de araticum foram utilizados para o cálculo das distâncias ou dissimilaridades genéticas entre os acessos, com o auxílio do Programa Genes (CRUZ, 2008), utilizando-se da seguinte expressão:

DGij $=1-[C V i j /(C V i j+D V i j)]$ em que:

DGij= Dissimilaridade genética entre os acessos i e j;

CVij= Número de coincidências de valores das classes das $n$ características categóricas analisadas entre os acessos i e j;

DVij= Número de discordâncias de valores das classes das $n$ características categóricas analisadas entre os acessos i e j,

Análises de Correlação, Agrupamento e Dispersão com base nas matrizes de dissimilaridades genéticas

Para comparar as dissimilaridades genéticas entre os acessos de araticum obtidas com base em marcadores moleculares RAPD, microssatélites e características morfológicas categóricas, foram calculados coeficientes de correlação de Pearson entre as dissimilaridades genéticas, com auxílio do Programa Genes (CRUZ, 2008).

As matrizes de dissimilaridades genéticas obtidas com base em cada tipo de marcador molecular e as características morfológicas foram utilizadas para realizar a análise de agrupamento com o auxílio do Programa Statistica (STATSOFT INC., 1999), utilizando como critério de agrupamento o método do UPGMA. Ainda com base em cada uma das matrizes de dissimilaridades genéticas, foi realizada a dispersão gráfica baseada em escalas multidimensionais, usando o método das coordenadas principais, com auxílio do Programa SAS e Statistica (STATSOFT INC., 1999).

\section{RESULTADOS E DISCUSSÃO}

Os 10 iniciadores decâmeros geraram um total de 146 marcadores RAPD, perfazendo uma média de 14,6 marcadores por iniciador. Todos os marcadores RAPD obtidos foram polimórficos. As dissimilaridades genéticas entre os 18 genótipos de araticum variaram entre 0,152 e 0,697 (dados não apresentados). A menor dissimilaridade foi observada entre o genótipo CPAC AR 1-3 e CPAC AR 1-4 $(0,152)$, o que já era esperado por terem origem da mesma matriz (CPAC AR 1). As análises de agrupamento e dispersão gráfica (Figura 1) mostram que a dissimilaridade entre os acessos da coleção de trabalho da Embrapa Cerrados é menor em relação aos outros acessos.

A maior dissimilaridade $(0,697)$ foi entre o genótipo do out group (Terra Fria) e o acesso CPAC AR 9 (Águas Emendadas). Foram verificados outros coeficientes de dissimilaridades genéticas altos, evidenciando a ampla base genética, considerando todos os acessos analisados. Blanco et al. (2007) colocam que é importante considerar, também, que a alta proporção da variabilidade genética encontrada dentro das populações deve ser interpretada como resultante de elevadas taxas de fluxo gênico que devem ter operado no passado. A forte fragmentação do bioma Cerrado na atualidade, certamente, representa uma barreira sobre a qual dificilmente mudanças poderiam ocorrer nessa espécie, sobretudo entre populações separadas por centenas de quilômetros.

Analisando apenas o grupo de acessos já introduzidos há mais tempo na Embrapa Cerrados, as dissimilaridades entre eles são mais baixas, mostrando que a base genética da atual coleção de trabalho é mais estreita. Os acessos utilizados como outgroup foram os que mais diferiram dos outros, com maiores valores de dissimilaridade genética e posicionamento mais isolado no gráfico de dispersão (Figura 1B). Os outros acessos de localidades próximas ao Distrito Federal mostraram ampla variabilidade genética, sendo importantes para a ampliação da base genética da atual coleção de trabalho da Embrapa Cerrados.

Com base nos marcadores microssatélites, a análise de nove locos gerou informações sobre 33 alelos. O número de alelos por loco variou de 2 a 5, com uma média de 3,67 alelos por loco. As análises de agrupamento com base na matriz de dissimilaridade mostraram a formação de três grupos, bem semelhantes aos obtidos com base na matriz de dissimilaridade genética calculada, utilizando marcadores moleculares RAPD. O primeiro grupo é formado pelos acessos coletados em áreas de reservas, próximas ao Distrito Federal, com algumas exceções; o segundo, pelos acessos do CPAC; e o terceiro, pelos acessos do outgroup (Figura 2A).

Como havia sido verificado com base nos marcadores RAPD, os marcadores microssatélites também mostraram que os dois acessos utilizados como outgroup (Paranã e de Terra Fria) apresentaram distâncias genéticas elevadas em relação aos demais acessos (Figuras 1 e 2). Segundo Pereira et. al (2008), existe uma barreira geográfica que pode impedir o fluxo gênico entre algumas regiões do Estado de Goiás localizadas no Vão do Paranã. Esta hipótese é sustentada pela elevada magnitude da 
dissimilaridade genética observada entre populações situadas em margens opostas, em contraposição à baixa distância geográfica entre elas, e, ainda, pela reduzida magnitude das dissimilaridades genéticas entre populações situadas na mesma margem. Esses dados foram fundamentados em estudos genéticos com microssatélites. Os resultados deste trabalho corroboram uma possível regionalização da variabilidade genética, o que também foi verificado por Ferreira (2011) em estudos de populações do Estado de Minas Gerais com base em marcadores microssatélites. Estas informações mostram a importância da coleta de acessos de diferentes regiões para o aumento da variabilidade genética de coleções de trabalho e bancos de germoplasma da espécie. Blanco et al. (2007) enfatizam a elevada diversidade genética em termos de polimorfismos de DNA cloroplastidial, mesmo nas populações de Annona crassiflora isoladas geograficamente no Estado de Goiás.

$\mathrm{Na}$ análise das características morfológicas categóricas, os acessos CPAC AR-1-1, CPAC AR1-2; CPAC AR-1-3, e CPAC AR-1-4 não foram utilizados por serem ainda de plantas muito jovens. A análise morfológica categórica mostrou maior divergência dos acessos quanto ao ápice da folha, formato de folha e tamanho de pecíolo, com variação de 5 e 4 classes, respectivamente. De acordo com Cohen et al. (2010), a julgar pela variabilidade morfológica encontrada nos frutos (peso, forma e volume) e na polpa (cor, consistência e sabor), podese inferir que há grande variabilidade genética do araticum no ambiente de ocorrência natural.

Os acessos utilizados como outgroup, mais uma vez, ficaram isolados do resto do grupo, mas houve uma aproximação com o acesso CPAC AR-6 (Figura 3). Tanto os acessos do outgroup quanto o acesso CPAC AR-6 foram implantados no mesmo campo experimental da Embrapa Cerrados de cultivos consorciados. É provável que essa similaridade morfológica possa ser explicada por um possível efeito ambiental, considerando a proximidade das áreas onde elas estão plantadas, com mesmo tipo de solo, vento, quantidade de água e tratos culturais. Pôde-se observar também que, nas análises com base em marcadores moleculares RAPD e microssatélites, esse acesso apresentava certa divergência dos demais, mas não se aproximava dos acessos do outgroup.

O acesso Jardim ACN (CPAC AR-7) e o do viveiro (CPAC AR-1) apresentaram alta similaridade com base nas características morfológicas (Figura 3). Estes acessos foram introduzidos na Embrapa Cerrados na mesma época e estão submetidos a condições ambientais bem parecidas.

Estatísticas descritivas das dissimilaridades genéticas obtidas com base nos diferentes grupos de características mostram a amplitude das distâncias e um maior coeficiente de variação para as dissimilaridades genéticas obtidas com base em marcadores SSR (29,7\%), seguida das obtidas com base em marcadores RAPD (22,3\%). A maior amplitude das dissimilaridades genéticas também foi obtida com base nos marcadores microssatélites. Esta maior capacidade de diferenciação entre acessos dos marcadores microssatélites em relação aos marcadores RAPD também foi verificada por Faleiro et al. (2004).

Coeficientes de correlação de Pearson entre as medidas de dissimilaridade calculadas com base em diferentes tipos de características demonstraram correlação positiva de $0,47 \mathrm{e}$ significativa (Prob $<0,01$ pelo teste $t$ ) entre as dissimilaridades calculadas com base em marcadores moleculares RAPD e microssatélites, o que também foi verificado por Faleiro et al. (2004). As correlações entre as dissimilaridades calculadas com base em características morfológicas categóricas e as dissimilaridades calculadas com base em marcadores moleculares foram negativas. Estas correlações evidenciam, de um lado, a relação entre as características obtidas com base em marcadores moleculares e, de outro, a não relação destas características com as morfológicas categóricas. Nesse sentido, podemos dizer que existe uma complementaridade das características morfológicas e baseadas no DNA para estudos de diversidade genética.

É importante salientar que alguns acessos foram analisados em seu ambiente natural. Possivelmente, o ambiente teve uma interferência significativa nas características morfológicas categóricas dos acessos. A utilização somente da análise in situ de um acesso é muito arriscada, principalmente quando estão sendo comparados diferentes acessos oriundos de diferentes ambientes. Neste caso, o ambiente pode ter uma forte influência no fenótipo, ou seja, nas expressões das características morfológicas das plantas. $\mathrm{O}$ uso de diferentes tipos de características de forma complementar é o melhor caminho para a caracterização de recursos genéticos e estudos de diversidade genética, sendo que o uso de marcadores moleculares do DNA é estratégico por eles não terem influência do ambiente e permitirem a obtenção de um número praticamente ilimitado de polimorfismos genéticos obtidos diretamente do DNA (FALEIRO, 2007). 
TABELA 1- Acessos de araticum e sua respectiva origem.

\begin{tabular}{ccc}
\hline Número & Código & Locais de coleta \\
\hline 1 & CPAC AR-9 & Águas Emendadas \\
2 & CPAC AR-11 & Colégio Agrícola \\
3 & CPAC AR-15 & Cabeceiras - GO \\
4 & CPAC AR-16 & Cabeceiras - GO \\
5 & CPAC AR-26 & Reserva do Exército \\
6 & CPAC AR-27 & Reserva do Exército \\
7 & CPAC AR-31 & Reserva do Exército \\
$8^{*}$ & CPAC AR-7 & Jardim ACN \\
$9^{*}$ & CPAC AR-8 & Jardim transportes \\
$10^{*}$ & CPAC AR-1 & Viveiro CPAC \\
$11^{*}$ & CPAC AR-1-1 & Viveiro CPAC \\
$12^{*}$ & CPAC AR-1-2 & Viveiro CPAC \\
$13^{*}$ & CPAC AR-1-3 & Viveiro CPAC \\
$14^{*}$ & CPAC AR-1-4 & Viveiro CPAC \\
15 & CPAC AR-5 & Consórcio \\
16 & CPAC AR-6 & Consórcio \\
17 & Out group & Paranã \\
18 & Out group & Terra Fria \\
\hline
\end{tabular}

* Acessos da coleção de trabalho da Embrapa Cerrados

TABELA 2- Primers utilizados para obtenção de marcadores moleculares microssatélites de acessos de araticum e respectivas temperaturas de anelamento.

\begin{tabular}{clll}
\hline \multirow{2}{*}{ Loci } & \multicolumn{2}{c}{ Primers } & \multirow{2}{*}{ Sequência Foward } \\
\cline { 2 - 3 } & \multicolumn{1}{c}{ Tequência Reverse } & \\
\hline Acr 01 & CGGCCTTCAAAAAGGGAGATA & CATGATTCTTCTGCTTCTGTGG & $60^{\circ} \mathrm{C}$ \\
Acr 10 & TGACGAAAACGAGAAAAGCA & ATGTCCCCACCCAATACAT & $60^{\circ} \mathrm{C}$ \\
Acr 19 & GAGAGCTGGGAGAAGAGCAA & AAAGCTGGGAGAGACGACAC & $60^{\circ} \mathrm{C}$ \\
Acr 20 & AGAGCCAGAGCCAGTGAGAC & TTGCCTCCATCTCTCAATCC & $60^{\circ} \mathrm{C}$ \\
Acr 22 & CTGACTCGCTGGCTCTCTCT & CTACAGCCCACATGTGCAAC & $60^{\circ} \mathrm{C}$ \\
Acr 26 & CACGACCAAGGAGAGAGGAG & GGCAACAATCCTGACTCACA & $58^{\circ} \mathrm{C}$ \\
Acr 33 & CAAACAGGCGATGAGACAGA & TGGTTGGCTTTTCTCTTCAA & $58^{\circ} \mathrm{C}$ \\
Acr 34 & GGAACAGAAGCTGTGGCATT & CGCGCAATTCCACAATAAC & $58^{\circ} \mathrm{C}$ \\
Acr 37 & GGCAACTTCTCCCCTTTACC & CCGGTGCCTGCTGTATATG & $60^{\circ} \mathrm{C}$ \\
\hline
\end{tabular}


TABELA 3-Descritores morfológicos categóricos ${ }^{1}$ utilizados na caracterização do araticum.

\begin{tabular}{|l|}
\hline Fuste \\
\hline A. Crescimento \\
1. Monopodial \\
2. Simpodial \\
\hline B.Aspecto \\
1. Reto \\
2. Tortuoso \\
3. Abaulado \\
4. Protuberancias \\
5. Base cilíndrica \\
6. Base achatada \\
\hline C. Cor \\
1. Cinza claro/escuro \\
2. Cinza claro \\
3. Castanho/cinza \\
\hline
\end{tabular}

\begin{tabular}{|l|}
\hline Ritidoma \\
\hline D. cor \\
1. Cinza claro \\
2. Castanho/cinza \\
\hline E. Tipo \\
1. Reticulado \\
2. Rugoso \\
3. Áspero \\
4. Liso \\
5. Escamoso \\
6. Com depressões \\
7. Laminado \\
8. Fissurado \\
9. Fendido \\
10. Estriado \\
\hline
\end{tabular}

\begin{tabular}{|l|}
\hline Copa \\
\hline F. Formato \\
1. Irregular \\
2. Cônica \\
3. Leque \\
4. Pendente \\
5. Colunar \\
6. Umbelada \\
\hline
\end{tabular}

\begin{tabular}{|l|}
\hline Ramos \\
\hline G. Característica \\
1. Lenticelados \\
2. Glabros \\
3. Rugoso \\
4. Pilosos \\
\hline
\end{tabular}

\begin{tabular}{|l|l|l|}
\hline \multicolumn{3}{|c|}{ Folha } \\
\hline H. Composição & Q.Ápice & Z. Formato (Campdód.) \\
1. Folha simples & 1. Arredondada & 1. Bronquidódroma \\
2. Composta & 2. Mucronada & 2. Eucampdódroma \\
\hline I. Exsudação & 3. Obtuso & 3. Reticulódroma \\
1. Ausente & 4. Agudo & 4. Cladódroma \\
\hline
\end{tabular}

2. Presente

5. Retuso

6. Acuminado

7. Truncado

2. $1,7-1,99$
3. $2-3$

4. $>3$

L. Formato

1. Largo-elíptica

2. Elíptica

3. Estreito-oblonga

4. Estreito-ovada

5. Largo-oblonga

6. Estreito-oblonga

7. Estreito-obovada

8. Ovada

9. Estreito-obvada

10. Lanceolada

M. filotaxia/disposição

1. Altemas dísticas

2. Altemas espiraladas

3. Opostas cruzadas

R. Base

1. Arredondada

2. Aguda

3. Cordada

4. Lobada

5. Obtusas

S. Estípula

1. Intrapeciolares

2. Ausente

T. Textura

1. Coriácea

2. Cartácea

3. Membranácea

U. Coloração

1. Concolor

2. Discolor

\begin{tabular}{|l|} 
4. Opostas disticas \\
5. Verticeladas \\
\hline
\end{tabular}

\begin{tabular}{|l|}
\hline N. Pilosidade \\
1. Glabras \\
2. Pulverulento \\
\hline O. Peciolo
\end{tabular}

O. Pecíolo

V. Nervura Adaxial (12nerv $/ \mathbf{2}^{\mathbf{x}}$ nerv.)

1. Saliente/Imersa

2. Impressa/saliente

3. Impressa/Impressa

4. Impressa/Imersa

5. Imersa/Imersa

6. Saliente/saliente

7. Imersa/saliente

1. $0,3-0,49 \mathrm{~cm} \quad$ 8. Imersa/saliente

2. $0,5-0,69 \mathrm{~cm}$

3. $0,7-0,99 \mathrm{~cm}$

4. $>1 \mathrm{~cm}$

\section{P. Margem}

1. Inteira

2. Ciliadas

3. Dentadas

4. Lobadas

5. Palmadas

6. Serrilhada

7. Revoluta
9. Saliente/impressa

\section{Nervura Abaxial (1'nerv $/ 2^{2}$ nerv.)}

1. Saliente/saliente

2. Saliente/impressa

3. Saliente/imersa

4. Impressa/saliente

5. Impressa/Impressa

6. Impressa/Imersa

7. Imersa/Imersa

8. Imersa/saliente

9. Imersa/saliente

${ }^{1}$ Descritores selecionados com base no Guia do observador de árvores do Cerrado, elaborado por Manoel Cláudio da Silva Júnior para curso de observadores de árvores do Cerrado. 

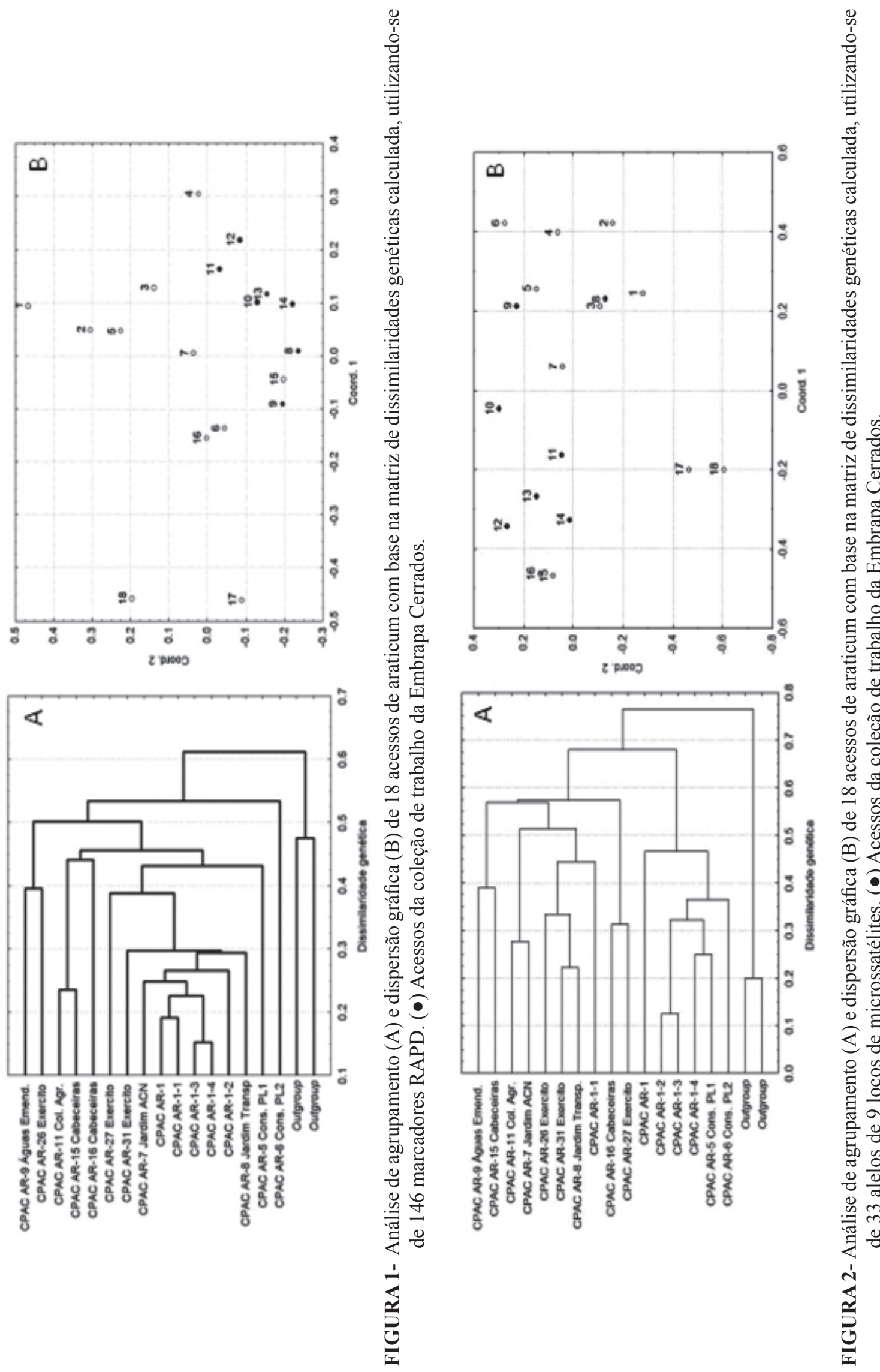

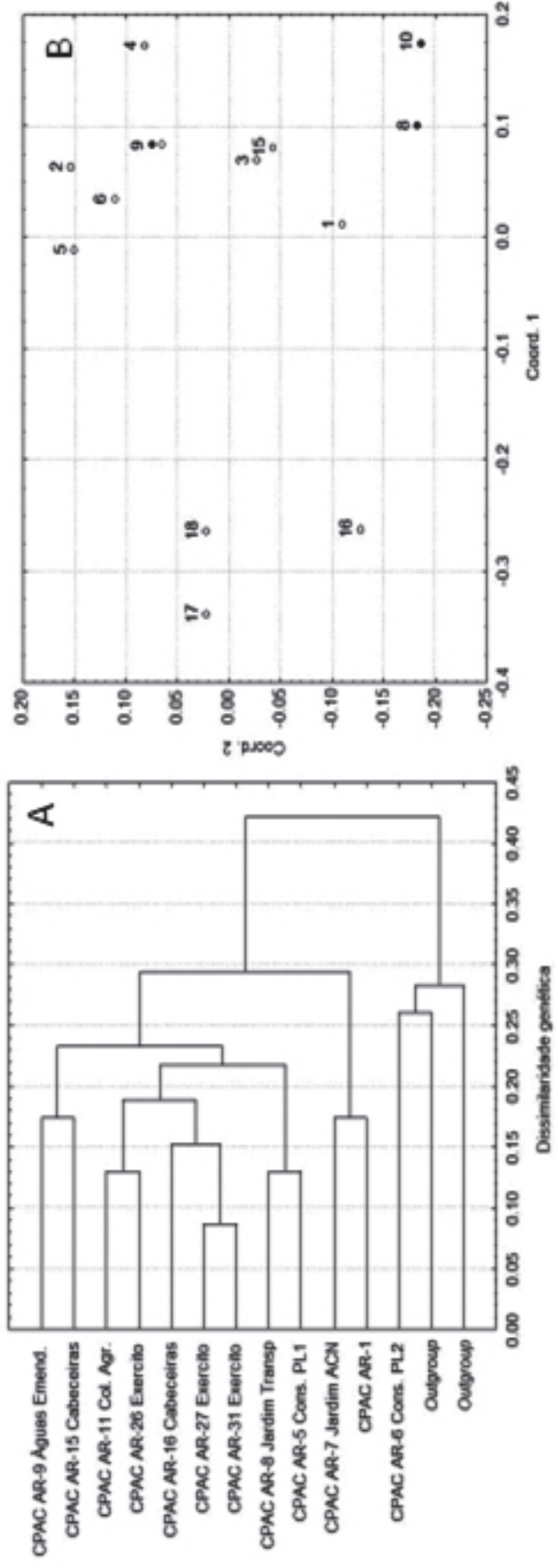

\section{CONCLUSÕES}

Existe alta variabilidade genética molecular e morfológica entre acessos das reservas de Águas Emendadas, do Exército, do Colégio Agrícola e de acessos da coleção de trabalho da Embrapa Cerrados implantados em áreas experimentais e de cultivos consorciados. Os acessos da coleção de trabalho da Embrapa Cerrados demonstraram maior proximidade genética entre si do que em relação aos demais acessos. Houve interferência significativa do ambiente nas características morfológicas dos acessos de araticum avaliados. Este resultado ressalta que, para os trabalhos de caracterização morfoagronômica, é essencial diminuir os efeitos ambientais nas características e, para isso, a montagem de bancos ativos de germoplasma com repetições (progênies ou clones) dos diferentes acessos em diferentes locais assume importância estratégica para os trabalhos iniciais de seleção ou pré-melhoramento.

\section{REFERÊNCIAS}

ALMEIDA, S. P. de; PROENÇA, C. E. B.; SANO, S. M.; RIBEIRO, J. F. Cerrado: espécies vegetais úteis. Planaltina: Embrapa-CPAC, 1998. 464 p.

BERNARDES, T. G.; ESTRÊLA, C. T.; NAVES, R. V.; REZENDE, C. F. A.; MESQUITA, M. A. M.; PIRES, L. L. Efeito do armazenamento e de fitohormônios na qualidade fisiológica de sementes de araticum (Annona crassiflora Mart.). Pesquisa Agropecuária Tropical, Goiânia, v. 37, n. 3, p. 163-168, 2007.

BLANCO, A. J. V.; PEREIRA, M. de F.; COELHO, A. S. G.; CHAVES, L. J. Diversidade genética em populações naturais de araticunzeiro (Annona crassiflora Mart.) por meio da análise de sequências de CpDNA. Pesquisa Agropecuária Tropical, Goiânia, v. 37, n. 3, p. 169-175, 2007.

CAVALCANTE, T. R. M.; NAVES, R. V.; FRANCESCHINELLI, E. V.; SILVA, R. P. Polinização e formação de frutos em araticum. Bragantia, Campinas, v. 68, n. 1, p. 13-21, 2009.

COHEN, K.O.; SANO, S.M.; SILVA, J.C.S.; MELO, J.T. Avaliação das características físicas e físico-químicas dos frutos de araticum provenientes de Cabeceiras-GO. Planaltina: Embrapa Cerrados, 2010. 16 p. (Boletim de Pesquisa e Desenvolvimento, 270). 
COTA, L. G.; VIEIRA, F. A.; MELO JÚNIOR, A. F.; BRANDÃO, M. M.; SANTANA, K. N. O.; GUEDES, M. L.; OLIVEIRA, D. A. Genetic diversity of Annona crassiflora (Annonaceae) in northern Minas Gerais State. Genetics and Molecular Research, Ribeirão Preto, v. 10, n.3, p. 2.172-2.180, 2011.

CRUZ, C. D. Programa genes: diversidade genética. Viçosa: UFV, 2008. 278p.

FALEIRO, F. G.; PIRES, J. L.; MONTEIRO, W. R.; LOPES, U. V.; YAMADA, M. M.; PIEDRA, A. G.; MOURA, A.D.; ARÉVALO-GARDINI, E.; MARQUES, J. R. B.; GRAMACHO, K. P.; FALEIRO, A. S. G.; SANTOS, M. C. M. Variability in cocoa accessions from the Brazilian, Ecuadorian, and Peruvian Amazons based on molecular markers. Crop Breeding and Applied Biotechnology, Viçosa, MG, v. 4, p. 227-233, 2004.

FALEIRO, F.G. Marcadores genético-moleculares aplicados aos programas de conservação e uso de recursos genéticos. Planaltina: Embrapa Cerrados, 2007. 102p.

FALEIRO, F.G.; FALEIRO, A.S.G.; CORDEIRO, M.C.R.; KARIA, C.T. Metodologia para operacionalizar a extração de DNA de espécies nativas do cerrado. Planaltina: Embrapa Cerrados, 2003. 6 p. (Comunicado Técnico,92).

FALEIRO, F.G.; JUNQUEIRA, N.T.V. Recursos genéticos: conservação, caracterização e uso. In: FALEIRO, F.G.; ANDRADE, S.R.M.; REIS JÚNIOR, F.B. Biotecnologia: estado da arte e aplicações na agropecuária. Planaltina: Embrapa Cerrados, 2011. p.513-551.

FERREIRA, M.F.M. Análises genéticas de Annona crassiflora (Annonaceae): implicações para a conservação da espécie. 2011. 127 f. Dissertação (Mestrado) - Universidade Federal de Lavras, Lavras, 2011.
INOUE, M. H.; SANTANA, D.C.; SOUZA FILHO, A. P. S.; POSSAMAI, A. C. S.; SILVA, L. E.; PEREIRA, M. J. B.; PEREIRA, K. M. Potencial alelopático de Annona crassiflora: efeitos sobre plantas daninhas. Planta Daninha, Viçosa, MG, v. 28, n.3, p. 489-498, 2010.

JUNQUEIRA, N.T.V.; FALEIRO, F.G.; BRAGA, M.F.; PEIXOTO, J.R. Domesticação de espécies da flora nativa do Cerrado. In: PARRON, L.M.; AGUIAR, L.M.S.; DUBOC, E.; OLIVEIRA FILHO, E.C.; CAMARGO, A.J.A.; AQUINO, F.G. (Ed.). Cerrado: desafios e oportunidades para o desenvolvimento sustentável. Planaltina: Embrapa Cerrados, 2008. p.125-163.

MESQUITA, M. A. M.; NAVES, R.V; SOUZA, E. R. B. de; BERNARDES, T. G.; SILVA, L. B. e. Caracterização de ambientes com alta ocorrência natural de araticum (Annona crassiflora Mart.) no Estado de Goiás. Revista Brasileira de Fruticultura, Jaboticabal, v. 29, n. 1, p. 15-19, 2007.

OLIVEIRA, M.C.; PEREIRA, D.J.S.; RIBEIRO, J.F. Viveiro e produção de mudas de algumas espécies arbóreas nativas do cerrado. Planaltina: Embrapa Cerrados, 2011. 6 p. (Documentos, 147).

PEREIRA, M. F.; BANDEIRA, L. F.; BLANCO, A. J. V.; CIAMPI, A.Y.; COELHO, A. S. G. Development of microsatellite markers in Annona crassiflora Mart., a Brazilian Cerrado fruit tree species. Molecular Ecology Resources, Oxford, v. 8, p.1329-1331, 2008.

RIBEIRO, L. R. Citogenética e efeitos citogenotóxicos de Annona crassiflora Mart. (Annonaceae). 2012. $91 \mathrm{f}$. Tese (Doutorado) Universidade Federal de Lavras, Lavras, 2012.

ROESLER, R.; MALTA,L. G.; CARRASCO, L. C.; HOLANDA, R. B.; SOUSA, C. A. S.; PASTORE, G. M.Atividade antioxidante de frutas do cerrado. Ciência e Tecnologia de Alimentos, Campinas, v.27, n.1, p.53-60, 2007.

STATSOFT. Statistica for windows [Computer program manual]. Tulsa, 1999. 